\title{
Association of plasma sRAGE, but not esRAGE with lung function impairment in COPD
}

\author{
Poornima Gopal', Niki L Reynaert', Jean L J M Scheijen³ ${ }^{3}$, Casper G Schalkwijk ${ }^{3}$, Frits M E Franssen², \\ Emiel F M Wouters ${ }^{1,2}$ and Erica P A Rutten ${ }^{2^{*}}$
}

\begin{abstract}
Rationale: Plasma soluble Receptor for Advanced Glycation End Product (sRAGE) is considered as a biomarker in COPD. The contribution of endogenous sRAGE (esRAGE) to the pool of plasma sRAGE and the implication of both markers in COPD pathogenesis is however not clear yet. The aim of the current study was therefore to measure plasma levels of esRAGE comparative to total sRAGE in patients with COPD and a control group. Further, we established the relations of esRAGE and total SRAGE with disease specific characteristics such as lung function and $\mathrm{D}_{\mathrm{L}} \mathrm{CO}$, and with different circulating AGES.
\end{abstract}

Methods: Plasma levels of esRAGE and sRAGE were measured in an 88 patients with COPD and in 55 healthy controls. $\mathrm{FEV}_{1}$ (\%predicted) and FEV ${ }_{1} N C$ (\%) were measured in both groups; $\mathrm{D}_{\mathrm{L}} \mathrm{CO}$ (\%predicted) was measured in patients only. In this study population we previously reported that the AGE $N^{\varepsilon}$-(carboxymethyl) lysine (CML) was decreased, $\mathrm{N}^{\varepsilon}$ (carboxyethyl) lysine (CEL) increased and pentosidine was not different in plasma of COPD patients compared to controls.

Results: Plasma esRAGE (COPD: $533.9 \pm 412.4$, Controls: $848.7 \pm 690.3 \mathrm{pg} / \mathrm{ml} ; p=0.000$ ) was decreased in COPD compared to controls. No significant correlations were observed between plasma esRAGE levels and lung function parameters or plasma AGEs. A positive correlation was present between esRAGE and total sRAGE levels in the circulation. Confirming previous findings, total sRAGE (COPD: $512.6 \pm 403.8$, Controls: $1834 \pm 804.2 \mathrm{pg} / \mathrm{ml} ; p<0.001)$ was lower in patients compared to controls and was positively correlated FEV $(r=0.235, p=0.032), \mathrm{FEV}_{1} N C(r=0.218, p=0.047)$, and $D_{L} C O(r=0.308, p=0.006)$. sRAGE furthermore did show a significant positive association with $C M L(r=0.321$, $p=0.003)$.

Conclusion: Although plasma esRAGE is decreased in COPD patients compared to controls, only total sRAGE showed a significant and independent association with $\mathrm{FEV}_{1}, \mathrm{FEV}_{1} N \mathrm{NC}$ and $\mathrm{D}_{\mathrm{L}} \mathrm{CO}$, indicating that total sRAGE but not esRAGE may serve as marker of COPD disease state and severity.

Keywords: sRAGE, esRAGE, FEV 1 , COPD

\section{Introduction}

Chronic obstructive pulmonary disease (COPD) is a major cause of morbidity and mortality. Long term inhalation of noxious gases including cigarette smoke leads to airflow obstruction and emphysema in the lungs. On the other hand persistent systemic inflammation and oxidative stress are common features of this disease. Currently, soluble Receptor for Advanced Glycation End products (sRAGE) is considered as a potential biomarker

\footnotetext{
* Correspondence: ericarutten@ciro-horn.nl

${ }^{2}$ Centre of expertise for chronic organ failure (Ciro+), PO Box 4080, Horn, the Netherlands

Full list of author information is available at the end of the article
}

for emphysema, based on data showing emphysema as independent predictor of decreased levels of sRAGE in the circulation of COPD patients [1,2].

RAGE is a transmembrane, multi ligand, patternrecognition receptor that belongs to the immunoglobulin super family of cell surface receptors $[3,4]$. The human RAGE gene (AGER) consisting of 11 exons, produces membrane RAGE (mRAGE) which comprises an extracellular, a transmembrane, and cytosolic domain. Alternative splicing of the $A G E R$ gene leads to the formation of endogenous soluble RAGE (esRAGE) [5]. On the other hand, ectodomain shedding of mRAGE by metalloproteinase such as MMP9 and A disintegrin and metalloprotease 
(ADAM) 10 generates soluble RAGE (sRAGE) [6,7]. Soluble forms of RAGE found in the circulation can act as decoy receptors for Advanced Glycation Endproducts (AGEs), preventing binding of AGEs to cell bound full length RAGE and downstream activation of NF- $\mathrm{\kappa B}$ [8].

Among many different extracellular ligands of RAGE, we previously examined levels of three different proteinbound AGEs in the plasma of COPD patients. In summary, $\mathrm{N}^{\varepsilon}$-(carboxymethyl) lysine (CML) was decreased, $\mathrm{N}^{\varepsilon}$-(carboxyethyl) lysine increased and pentosidine was not different in plasma of COPD patients compared to controls [9]. Literature survey shows that among several RAGE ligands investigated serum amyloid A (SAA), S100 protein A12 (S100A12) and High- mobility group protein B1 (HMGB1) were found to be increased in COPD patients compared to controls [10,11].

Although plasma sRAGE is considered as a biomarker for emphysema, no mechanisms have been proven to date that underlie this association. The most straightforward mechanism is that the lower plasma level of sRAGE is a reflection of the disappearance of pneumocytes which typically display very high RAGE expression [12]. A complicating factor is that it is assumed that the major soluble form of RAGE in the circulation is sRAGE. Recently however, a study identified an important contribution of esRAGE to total sRAGE as well as positive correlations of esRAGE to total sRAGE in BAL fluid and serum of asthmatics and COPD patients [13] Unfortunately, this manuscript did not report on differences in esRAGE levels between COPD patients and controls, or relations of esRAGE to disease markers.

In order to gain further evidence for plasma sRAGE as a potential biomarker in COPD, we measured plasma levels of esRAGE in patients with COPD and a control group. Furthermore, we established possible relations of esRAGE with different circulating AGEs, and disease specific characteristics such as lung function, $\mathrm{D}_{\mathrm{L}} \mathrm{CO}$ and use of external oxygen. Circulating sRAGE levels were measured as well to identify the contribution of esRAGE to total sRAGE.

\section{Methods}

\section{Study population}

The study population included 88 moderate to severe COPD patients referred for pulmonary rehabilitation, and 55 healthy controls who were recruited in Ciro+, center of expertise for chronic organ failure, Horn, the Netherlands. Clinical history of COPD and the degree of disease severity were assessed according to the Global Initiative for Chronic Obstructive disease guidelines $[14,15]$. Exclusion criteria were history of tumor, diabetes, and an exacerbation of the disease for $<4$ weeks before blood draw. Control subjects were judged healthy by a standardized health questionnaire. This study was approved by the local medical ethical committee of Maastricht University Medical Center, the Netherlands and was supported by lung foundation Netherlands under AF2009 project no: 3.2.09.049.

\section{Patient consent}

Patient consent: a written informed consent was taken from all study participants for the sake of publication.

The number of pack years (PY; the number of packs of cigarettes smoked per day divided by 20 multiplied by the number of years smoked) and the smoking status (never/ex-smoker) were recorded. People with 0 PY were considered never smokers, and who stopped smoking at least 1 year prior to recruitment was considered an exsmoker. Lung function was determined by spirometry, and post-bronchodilator forced expiratory volume in $1 \mathrm{sec}\left(\mathrm{FEV}_{1}\right)$ and forced vital capacity (FVC) were calculated from the flow-volume curve, and $\mathrm{FEV}_{1} / \mathrm{VC}$ was calculated and expressed as\%. Diffusion capacity of carbon monoxide $\left(D_{L} C O\right)$ was assessed by using singlebreath method (Masterlab ${ }^{\circ}$, Jaeger, Germany), expressed as \%predicted and used as an indirect marker for emphysema [14,16,17]. Height and weight were measured in every participant and body mass index (BMI) was calculated (weight divided by height ${ }^{2}\left(\mathrm{~kg} / \mathrm{m}^{2}\right)$ ). Use of long term oxygen treatment (LTOT) was recorded in the patients.

\section{Blood collection and determination of plasma markers}

Blood was collected in an evacuated tube containing EDTA (Sherwood Medical, St Louis, Missouri, USA) and immediately centrifuged at $800 \mathrm{rpm}$ for $10 \mathrm{~min}$ at $4^{\circ} \mathrm{C}$. The plasma samples were subsequently stored at $-80^{\circ} \mathrm{C}$ until analysis. Plasma esRAGE (B-Bridge international Inc., UK) and sRAGE (R\&D systems, Minneapolis, USA) were measured by ELISA. Plasma protein-bound CML and CEL were measured by liquid chromatography tandem mass spectrometry [18] and pentosidine was measured by HPLC with fluorescence detection [19] and expressed per lysine concentrations. Plasma levels of high density lipoproteins (HDL), triglycerides, glucose, $\mathrm{C}$-reactive protein (CRP) and creatinine were measured in an auto-analyzer (ABX Pentra 400, HORIBA ABX S.A.S, France). Glomerular filtration rate (GFR) was calculated using the Cockcroft-Gault formula [20].

\section{Statistical methods}

SPSS (version 17, Chicago, IL) was used for data analysis. Variables with skewed distribution like esRAGE, sRAGE, $\mathrm{CRP}, \mathrm{FEV}_{1}$, pentosidine and triglycerides were log transformed before further analysis. Comparison of characteristics between groups was performed by unpaired student's $t$ or Chi-square tests, for continuous or categorical data, respectively (Table 1). Spearman correlations were 
performed to establish the association of esRAGE and sRAGE with AGEs (Table 2) and other measured parameters (Tables 3 and 4). Uni- and multivariate linear regression analysis was used to investigate the association of plasma esRAGE and sRAGE with lung function, $\mathrm{D}_{\mathrm{L}} \mathrm{CO}$ and LTOT. Primarily the parameters which showed a significant or a relevant (age and sex) association with esRAGE and sRAGE were included to build the regression models. Because of the co-linearity of the lung function parameters they were analyzed separately. All analysis were first adjusted for age, sex and GFR (models 1 and 2), next we evaluated the association of sRAGE and esRAGE with $\mathrm{FEV}_{1}$ or $\mathrm{FEV}_{1} / \mathrm{VC}$ (model 3), with $\mathrm{D}_{\mathrm{L}} \mathrm{CO}$ (model 4), and with LTOT (model 5).

\section{Results}

\section{General description of COPD and controls}

Table 1 describes the baseline characteristics of the study group. As expected, $\mathrm{FEV}_{1}$ was significantly lower in the COPD patients compared to the never and ex-smoking controls $(\mathrm{p}<0.001)$. Based on the GOLD criteria 34
Table 2 Correlations of sRAGE, esRAGE with AGEs in COPD

\begin{tabular}{lll}
\hline & esRAGE & sRAGE \\
\hline CML & $r=-0.034, p=0.785$ & $r=0.321, p=0.003$ \\
CEL & $r=-0.220, p=0.076$ & $r=-0.11, p=0.921$ \\
pentosidine & $r=-0.032, p=0.799$ & $r=0.106, p=0.347$ \\
\hline
\end{tabular}

patients were categorized GOLD II, 39 as GOLD III and 15 as GOLD IV. COPD patients had smoked more PY compared to ex-smoking controls. Furthermore, no differences were observed in the plasma levels of HDL, triglycerides, creatinine and GFR between patients and controls. Lastly, CRP was found to be increased in COPD patients compared to both control groups $(\mathrm{p}<0.001)$.

\section{Plasma esRAGE in COPD and controls}

Plasma esRAGE levels were significantly decreased in COPD patients compared to never and ex- smoking controls [never smoker: $1098 \pm 893$; ex-smoker: $781 \pm$ 626; COPD: $534 \pm 412, \mathrm{pg} / \mathrm{ml}$, (Figure $1 \mathrm{~A}$ )]. No effect of

Table 1 General characteristics of COPD patients and controls

\begin{tabular}{|c|c|c|c|}
\hline & $\begin{array}{l}\text { Never smoker controls, } \\
n=11\end{array}$ & $\begin{array}{l}\text { Ex-smoker controls, } \\
n=44\end{array}$ & COPD, $\mathrm{n}=88$ \\
\hline Age & $58 \pm 5.9$ & $61 \pm 5.4$ & $63 \pm 8^{\mathrm{E}, \mathrm{N}}$ \\
\hline Male, (n)\% & (3) 27.3 & (22) 50 & (46) 52.3 \\
\hline Pack years ${ }^{*}$ & $0 \pm 0$ & $15.6 \pm 13.3$ & $35.0 \pm 16.1^{\mathrm{E}, \mathrm{N}}$ \\
\hline Smoking status, $(\mathrm{n}) \%^{\S}$ & - & - & Ex-smoker (64) 72.7 Current smoker (18) 20.5 \\
\hline $\mathrm{BMl}, \mathrm{kg} / \mathrm{m}^{2}$ & $26.9 \pm 4.0$ & $27.52 \pm 4.0$ & $26.1 \pm 5.2$ \\
\hline $\mathrm{FEV}_{1} \%$ predicted & $114.5(104.0-120.0$ & $122.1(112.0-133.0)$ & $45.50(32.3-61.0)^{\mathrm{E}, \mathbf{N}}$ \\
\hline $\mathrm{FEV}_{1} \mathrm{NC} \%$ & $79.2(74.6-82.3)$ & $78.9(75.2-82.5)$ & $51.9(38.3-63.3)^{\mathrm{E}, \mathrm{N}}$ \\
\hline $\mathrm{D}_{\mathrm{L}} \mathrm{CO} \%$ predicted & - & - & $51.46(42.4-73.19)$ \\
\hline LTOT (n) & - & - & 16 \\
\hline Triglycerides, mg/dl & $92.2(85.1-109.0)$ & $93.0(71.8-135.6)$ & $100.1(84.2-136.9)$ \\
\hline $\mathrm{HDL}, \mathrm{mg} / \mathrm{dl}$ & $69.1 \pm 14.3$ & $68.5 \pm 20.5$ & $75 \pm 27$ \\
\hline CRP, mg/L & $0.6(0.1-0.9)$ & $0.7(0.3-1.8)$ & $3.4(1.7-8.5)^{\mathrm{E}, \mathrm{N}}$ \\
\hline \multicolumn{4}{|l|}{ Medication use } \\
\hline Long/short acting muscarinic receptor antagonist $(n) \%$ & & & $63(73.9)$ \\
\hline LABA, (n)\% & & & $40(45.5)$ \\
\hline SABA, (n)\% & & & $23(26.1)$ \\
\hline LABA + inhaled corticosteroids, (n)\% & & & $54(61.4)$ \\
\hline Inhaled corticosteroid, (n)\% & & & $11(12.5)$ \\
\hline Oral corticosteroid, (n)\% & & & $17(19.3)$ \\
\hline $\mathrm{N}$ - acetylcysteine, $(\mathrm{n}) \%$ & & & $9(10.2)$ \\
\hline Statins, $(n) \%$ & & & $22(20.6)$ \\
\hline
\end{tabular}

Unless otherwise stated all data are expressed as mean \pm SD or median (IQR).

p-value $<0.05$ between COPD patients and ex-smoking controls is noted as $\mathrm{E}$, and between COPD and never smoking controls as $\mathrm{N}$. "indicates history of pack year smoked is missing for 34 patients; smoking stop date is available for this group.

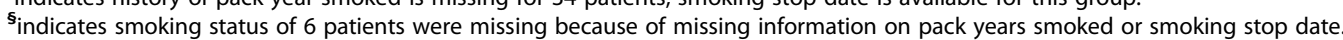
Abbreviations used: BMI, body mass index; $\mathrm{FEV}_{1}$, forced expiratory volume in 1 second; HDL, high density lipoproteins; CRP, C- reactive protein; LABA, long-acting beta agonists; SABA, short-acting beta agonists. 
Table 3 Linear regression analysis of COPD patients with plasma esRAGE as dependent variable

\begin{tabular}{|c|c|c|c|}
\hline Univariate analysis & B & $95 \% \mathrm{Cl}$ for $\mathrm{B}$ & $p$ value \\
\hline Age & 0.029 & 0.006 to 0.052 & 0.016 \\
\hline Sex & -0.255 & -0.637 to 0.127 & 0.187 \\
\hline Pack years & 0.001 & -0.012 to 0.014 & 0.925 \\
\hline BMI & 0.022 & -0.015 to 0.059 & 0.240 \\
\hline $\mathrm{FEV}_{1}$ & 0.007 & -0.004 to 0.018 & 0.220 \\
\hline $\mathrm{FEV}_{1} / \mathrm{NC}$ & 0.010 & -0.002 to 0.022 & 0.108 \\
\hline LTOT & 0.112 & -0.418 to 0.642 & 0.674 \\
\hline CRP & 0.015 & -0.010 to 0.040 & 0.246 \\
\hline$D_{L} C O$ & 0.012 & -0.002 to 0.026 & 0.092 \\
\hline GFR & -0.010 & -0.019 to 0.000 & 0.042 \\
\hline Multivariate analysis & B & $95 \% \mathrm{Cl}$ for $\mathrm{B}$ & $p$ value \\
\hline Model 1: Age + sex & -0.363 & -0.754 to 0.028 & 0.068 \\
\hline Model 2: model $1+$ GFR & -0.006 & -0.015 to 0.004 & 0.271 \\
\hline Model 3: model $2+\mathrm{FEV}_{1}$ & 0.002 & -0.011 to 0.015 & 0.784 \\
\hline Model 4: model $3+\mathrm{D}_{\mathrm{L}} \mathrm{CO}$ & 0.004 & -0.004 to 0.026 & 0.157 \\
\hline Model 5: model $4+$ LTOT & -0.011 & -0.665 to 0.644 & 0.974 \\
\hline Multivariate analysis & B & $95 \% \mathrm{Cl}$ for $\mathrm{B}$ & $p$ value \\
\hline Model 1: Age + sex & -0.265 & -0.638 to 0.107 & 0.068 \\
\hline Model 2: model $1+$ GFR & -0.007 & -0.019 to 0.006 & 0.287 \\
\hline Model 3: model $2+\mathrm{FEV}_{1} \mathrm{NC}$ & 0.007 & -0.006 to 0.020 & 0.314 \\
\hline Model 4: model $3+D_{L} C O$ & 0.009 & -0.008 to 0.025 & 0.292 \\
\hline Model 5: model $4+$ LTOT & 0.009 & -0.656 to 0.653 & 0.996 \\
\hline
\end{tabular}

$\mathbf{B}$ is unstandardized coefficient.

smoking was observed as the difference in plasma esRAGE levels between never smoking controls and exsmoking controls, and between ex-smoking patients and current smoking patients was not significant $(p=0.186$ and $p=0.340$ respectively). esRAGE furthermore was not different between GOLD stages (GOLD II: $554.4 \pm$ 340.8; GOLD III: $507.8 \pm 468.6$; GOLD IV:571.8 \pm 393.2 , $p=0.871)$ and plasma esRAGE levels did not show a significant correlation with $\mathrm{FEV}_{1}$ (Figure 1B), $\mathrm{FEV}_{1} / \mathrm{VC}$ (data not shown), and $\mathrm{D}_{\mathrm{L}} \mathrm{CO}$ (Figure 1C) in COPD patients.

\section{Plasma total sRAGE in COPD and controls}

Plasma total sRAGE was also significantly decreased in COPD patients compared to the never and ex-smoking controls [never smoker: $2531 \pm 1168$; ex-smoker: $1671 \pm$ 612; COPD: $512 \pm 403$ pg/ml, (Figure 2A)]. Plasma levels of total sRAGE were in addition found to be significantly lower in ex-compared to never-smoking controls $(p=$ 0.047), indicating an effect of smoking per se. In COPD patients on the other hand, no significant difference in plasma sRAGE levels between ex-smokers and current smokers was observed $(p=0.503)$. As previously shown,

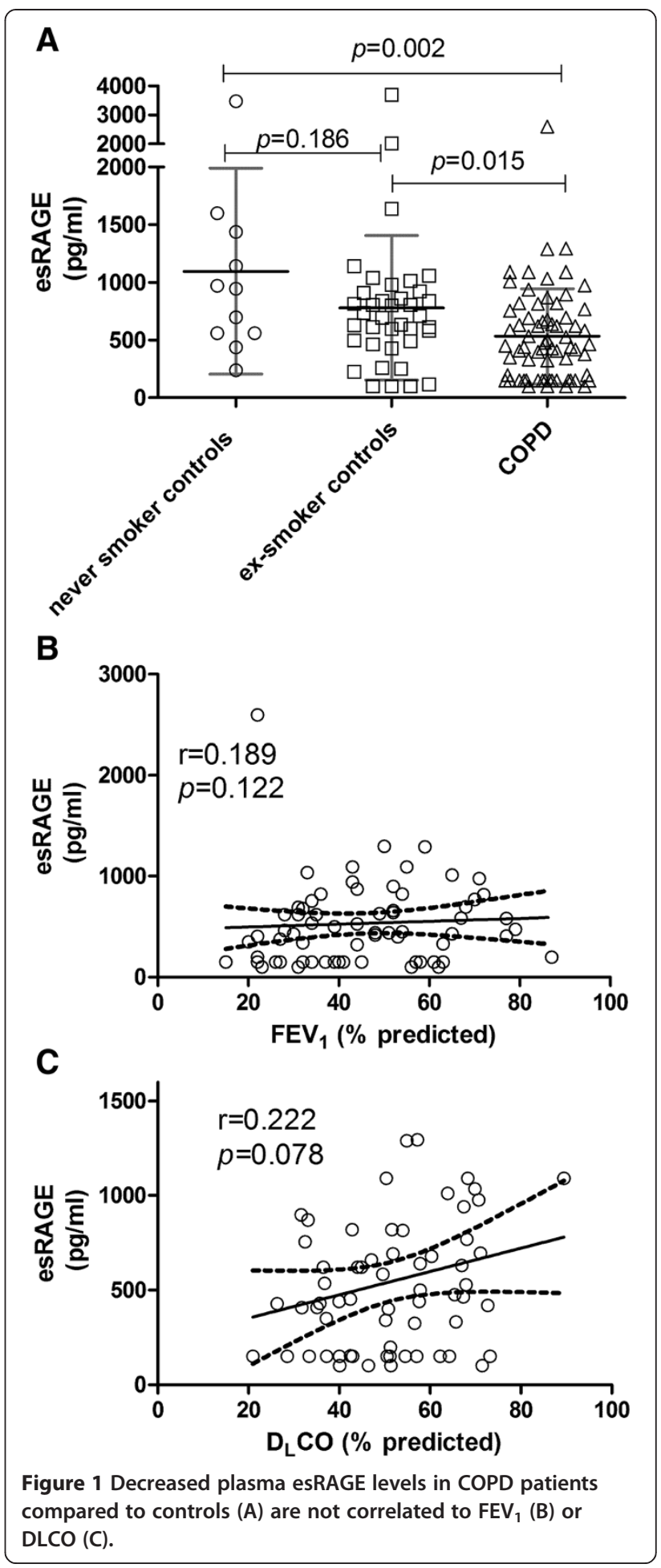

sRAGE was significantly different between GOLD stages (GOLD II: 677.4 \pm 576.8 ; GOLD III: $448.1 \pm 241.7$; GOLD IV:350.8 $\pm 144.9, p=0.013)$ and plasma total sRAGE showed a positive correlation with $\mathrm{FEV}_{1}(\mathrm{r}=$ $0.235, p=0.032$ (Figure 2B)) in COPD patients. A similar correlation was furthermore observed for $\mathrm{FEV}_{1} / \mathrm{VC}$ 


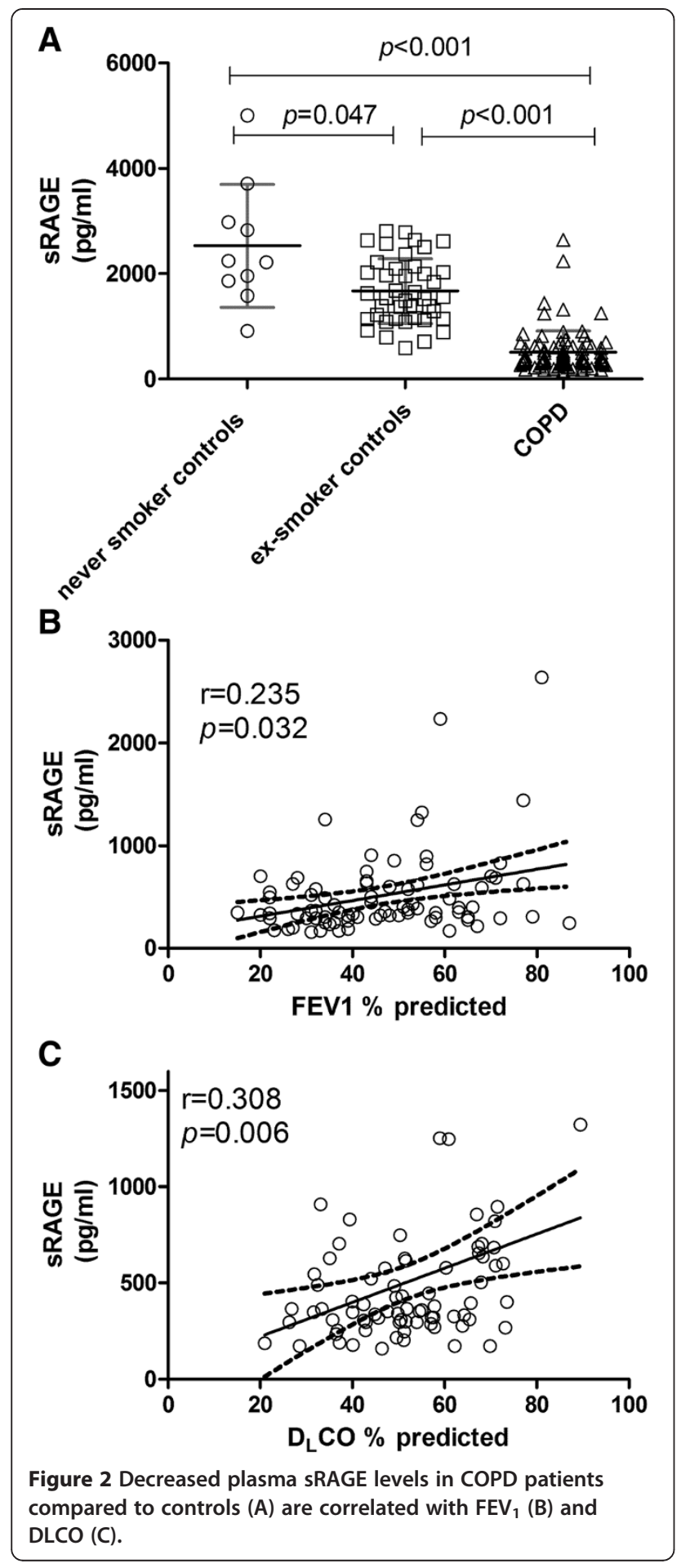

$(\mathrm{r}=0.218, \mathrm{p}=0.047$, Additional file 1: Figure S1), as well as for $\mathrm{D}_{\mathrm{L}} \mathrm{CO}(\mathrm{r}=0.308, p=0.006$ (Figure $2 \mathrm{C})$ ).

\section{Correlations of esRAGE, sRAGE, AGEs and CRP}

As expected, plasma esRAGE levels were positively correlated with total sRAGE levels. This correlation was found to be significant in the total study group $(r=0.436$, $\mathrm{p}<0.0001$, Additional file 2: Figure S2), as well as in the COPD patients $(\mathrm{r}=0.361, p<0.001$, Additional file 3 : Figure S3b), and in healthy controls $(\mathrm{r}=0.345, p=0.016$, Additional file 3: Figure S3a) individually.

No significant correlations were observed between plasma esRAGE levels and levels of AGEs in plasma. Plasma total sRAGE on the other hand was found to be positively correlated with plasma CML in COPD patients $(\mathrm{r}=0.321, p=0.003$ (Table 2)), but not in control subjects. Plasma CEL and pentosidine were furthermore not significantly associated with total sRAGE levels. In addition, neither esRAGE nor total sRAGE showed a significant correlation with plasma CRP (data not shown).

\section{Association of plasma esRAGE and sRAGE with lung function, $\mathrm{D}_{\mathrm{L}} \mathrm{CO}$ and LTOT}

Table 3 represents the outcome of the univariate analysis taking plasma esRAGE as dependent variable. Only age demonstrated a significant positive and GFR a significant negative association with plasma esRAGE levels. Multivariate analysis performed as outlined in Table 3, introducing either $\mathrm{FEV}_{1}$ or $\mathrm{FEV}_{1} / \mathrm{FVC}$ after correcting for age, sex and GFR as common confounders, demonstrate that the decrease in plasma esRAGE levels in COPD was not determined by any of the disease severity markers examined.

Similar uni- and multivariate analyses were performed for plasma total sRAGE. Results of the univariate analyses in Table 4 indicate significant positive associations of total sRAGE with $\mathrm{FEV}_{1}, \mathrm{FEV}_{1} / \mathrm{VC}$, and $\mathrm{D}_{\mathrm{L}} \mathrm{CO}$, and a negative association with LTOT. These variables were next used in multivariate analysis including age and sex as common confounders (model 1). Using this model, $\mathrm{FEV}_{1}$ showed a significant positive association with sRAGE [B: 0.010 (95\% CI: 0.003 to 0.017); $\mathrm{p}=0.006$ )]. When $\mathrm{D}_{\mathrm{L}} \mathrm{CO}$ was introduced in the model the association remained with statistical significance (model 3, Table 4). However, when LTOT (as a dichotomous variable) was added to the model the direction of the association changed in conjunction with a stronger $\mathrm{B}$ value [model 2, B: -0.414 (95\% CI: -0.781 to -0.047$) ; \mathrm{p}=0.028$ ). A similar analysis was performed separately for $\mathrm{FEV}_{1} / \mathrm{VC}$ resulting in similar outcomes (Table 4).

\section{Discussion}

The present study demonstrates decreased levels of esRAGE and total SRAGE in plasma of COPD patients compared to controls. Importantly, in COPD, total sRAGE and not esRAGE showed positive associations with $\mathrm{FEV}_{1}$, $\mathrm{FEV}_{1} / \mathrm{VC}$, and $\mathrm{D}_{\mathrm{L}} \mathrm{CO}$, and only sRAGE levels were negatively and independently associated with LTOT. Further, only total sRAGE levels were positively associated with CML, a major ligand of RAGE. 


\begin{tabular}{|c|c|c|c|}
\hline Univariate analysis & B & $95 \% \mathrm{Cl}$ for $\mathrm{B}$ & $p$ value \\
\hline Age & 0.010 & -0.005 to 0.025 & 0.190 \\
\hline Sex & -0.076 & -0.325 to 0.173 & 0.547 \\
\hline Pack years & 0.002 & -0.006 to 0.010 & 0.630 \\
\hline BMI & -0.008 & -0.032 to 0.015 & 0.480 \\
\hline $\mathrm{FEV}_{1}$ & 0.010 & 0.003 to 0.017 & 0.007 \\
\hline $\mathrm{FEV}_{1}$ NC & 0.012 & 0.004 to 0.019 & 0.004 \\
\hline LTOT & -0.329 & -0.640 to -0.017 & 0.039 \\
\hline GFR & -0.006 & -0.011 to 0.000 & 0.069 \\
\hline CRP & -0.004 & -0.019 to 0.011 & 0.584 \\
\hline$D_{L} C O$ & 0.014 & 0.006 to 0.023 & 0.002 \\
\hline Multivariate analysis & B & $95 \% \mathrm{Cl}$ for $\mathrm{B}$ & $p$ value \\
\hline Model 1: Age + sex & -0.096 & -0.345 to 0.153 & 0.444 \\
\hline Model 2: model $1+\mathrm{FEV}_{1}$ & 0.010 & 0.003 to 0.017 & 0.006 \\
\hline Model 3: model $2+D_{L} C O$ & 0.012 & 0.002 to 0.022 & 0.017 \\
\hline Model 4: model 3 + LTOT & -0.414 & -0.781 to -0.047 & 0.028 \\
\hline Multivariate analysis & B & $95 \% \mathrm{Cl}$ for $\mathrm{B}$ & $p$ value \\
\hline Model 1: Age + sex & -0.96 & -0.346 to 0.153 & 0.444 \\
\hline Model 2: model $1+\mathrm{FEV}_{1} \mathrm{NC}$ & 0.012 & 0.004 to 0.019 & 0.004 \\
\hline Model 3: model $2+D_{L} C O$ & 0.011 & 0.001 to 0.021 & 0.026 \\
\hline Model 4: model 3 + LTOT & -0.427 & -0.787 to -0.066 & 0.021 \\
\hline
\end{tabular}

B is unstandardized coefficient.

Most of the studies that report plasma sRAGE levels measured using a commercially available ELISA that detects total sRAGE, thus including esRAGE. Only one recent publication measured esRAGE separately in COPD. This study identified an important contribution of esRAGE to total sRAGE and positive correlations of esRAGE to sRAGE in BAL fluid and serum of asthmatics and COPD patients [13]. However, it did not report on differences in esRAGE levels between patients and controls, or relations to disease markers. Data from the present study confirm a moderate positive correlation of plasma esRAGE with total sRAGE levels and for the first time demonstrate decreased plasma esRAGE levels in COPD.

Two different mechanisms producing total sRAGE are by alternative splicing of $A G E R$ gene which results in secretion esRAGE, and by ectodomain shedding of membrane RAGE by MMP9/ADAM10 which leads to the secretion of sRAGE [21]. Both esRAGE and total sRAGE were observed to be lower in the circulation of COPD patients. Smoking per se seemed to affect total sRAGE levels as there was a significant difference between never and ex-smoking controls. This was however not the case for esRAGE (Figures 2A and 1A respectively), indicating that smoking affects shedding but not alternative splicing. Still it is important to further evaluate the effect of smoking as a cause for decreased sRAGE/esRAGE. Furthermore, the pattern of plasma sRAGE and esRAGE levels in the circulation of individual COPD patients and controls were found to be different. Based on these findings it is difficult to conclude whether alternative splicing or shedding or both are operational, since there is no literature on altered $A G E R$ gene expression and ADAM10 in the pulmonary/extra pulmonary compartment in COPD. However there is evidence in the literature of increased MMP9 protein levels in BAL of COPD patients [22,23], whereas an absence of difference in MMP9 levels and activity in the circulation of COPD patients was reported [24]. Further research is needed to determine whether altered gene expression, alternative splicing, and/or sheddases activity are responsible for decreased sRAGE levels in circulation.

Lowered levels of both esRAGE and sRAGE in the circulation of COPD patients could also be associated with the presence of functional single nucleotide polymorphisms (SNPs) in the AGER gene. Sequence variation studies have shown that there are 50 SNPs in 11 exons and 10 introns in the AGER gene. Among them rs2070600 [15] was associated with lower levels of plasma sRAGE in patients with diabetes and also in COPD [25,26]. Information regarding associations of circulating esRAGE levels with polymorphisms is limited. In type 2 diabetes it has been shown that rs2070600 and rs1800625 are associated with esRAGE levels in a Chinese cohort [27]. Given these genetic associations to circulating sRAGE levels in diseases affecting different primary organs and the contrasting increased pulmonary expression of RAGE in COPD patients, it remains questionable if lower systemic sRAGE levels indeed arise from altered pulmonary levels, and if so how [26,28]. There is one recent manuscript showing no decrease in plasma sRAGE level in patients with COPD with or without chronic heart failure [29], findings that are in contrast with many others, including our own showing decreased plasma total sRAGE levels in COPD [1,10,30].

Findings of the study presented here are in line with literature showing that plasma total sRAGE levels are associated with lung function in COPD [1,10,30,31]. In addition we evaluated whether comparable trends could be observed for esRAGE as both receptors have similar structures and functions, originating from the same gene through different mechanisms. In contrast to total sRAGE, we did however not find significant associations of plasma esRAGE with lung function parameters. Although the lack of $C T$ data is a limitation of the current study, the finding that $\mathrm{D}_{\mathrm{L}} \mathrm{CO}$ in most previous studies also correlated with plasma sRAGE levels, was replicated here as well. In addition we provide evidence that plasma total sRAGE levels are associated with the use of LTOT, even after adjustment for possible confounders and lung function. Again, such association with $D_{L} C O$ or oxygen use was not present for esRAGE. The 
mechanism of decreased systemic total sRAGE levels in COPD patients, and its association to alveolar damage is still not clear. From the results of the present study we can concluded that total sRAGE and not esRAGE resulting from splice variation of the $A G E R$ gene contributes to this association. Mechanisms involved in shedding of the receptor are likely involved, including via activation of sheddases like ADAM10 and MMP9, or via ligand engagement.

We investigated correlations of total sRAGE and esRAGE with measured plasma AGEs. The only significant correlation observed was between sRAGE and CML. RAGE ligands other than AGEs have been measured in the systemic circulation of patients with COPD. HMGB1, S100A12and SAA were found to be increased in COPD $[10,11,32]$, Among these ligands, only SAA showed a negative association with sRAGE. We previously reported decreased plasma CML levels in COPD and we showed here that this is positively correlated with sRAGE. Accelerated formation and accumulation of AGEs is due to inflammation and oxidative stress [33]. However, we previously found that alterations in plasma levels of CML were independent of CRP, as a marker of inflammation [9]. With our previous [30] and present data we furthermore did not find significant correlations of either sRAGE or esRAGE with CRP. Only one study was able to demonstrate a negative association of sRAGE with CRP in COPD [10], but a clear relationship between sRAGE and inflammation and oxidative stress has not been found so far. Further investigations are clearly needed that assess the association of sRAGE/esRAGE with comprehensive panels of RAGE ligands as well as inflammatory markers in large cohorts of patients.

In contrast to the recent attention given to sRAGE in lung research, little is known about the role of esRAGE in pulmonary physiology and pathology. It has been shown that not only vascular endothelial cells express esRAGE, but also neuronal, thyroid follicular, hepatocytes and pancreatic beta cells could be a possible source of circulating esRAGE [34]. Plasma levels are in addition determined by excretion via the kidneys. Plasma esRAGE is known to be strongly affected by renal insufficiency [35]; in agreement we observe a significant negative correlation of esRAGE with GFR. The current study shows decreased esRAGE levels in COPD, but no associations with disease characteristics. The observed decrease in esRAGE levels in COPD is important for future investigations into molecular mechanism behind the decreased levels of total sRAGE demonstrated often already and proposed as a biomarker for the disease, but still warrants further confirmation. Secondly, to establish whether systemic sRAGE alterations are causatively related to the development of structural emphysema or a systemically reflective consequence further longitudinal research is warranted in non-obstructed cigarette smokers.
In summary, both esRAGE and sRAGE are decreased in the circulation of COPD patients compared to controls. Only sRAGE showed a positive association with lung function and $\mathrm{D}_{\mathrm{L}} \mathrm{CO}$, a negative association with CML and was affected by oxygen treatment in COPD. We conclude that, although these molecules are products of the same gene they may have different roles in the pathogenesis of COPD and that primarily total sRAGE is a candidate biomarker for COPD phenotypes.

\section{Additional files}

Additional file 1: Figure S1. Plasma sRAGE levels in COPD correlated with $\mathrm{FEV}_{1} \mathrm{NC}$.

Additional file 2: Figure S2. Plasma levels of sRAGE and esRAGE in COPD correlated with each other.

Additional file 3: Figure S3. Decreased plasma esRAGE compared to sRAGE in (a) controls (b) COPD patients.

Competing interests

The authors declare that they have no competing interests.

\section{Authors' contributions}

ER and NR designed the study and ER provided the samples. PG and JS performed the analysis; CGS provided the equipment and reagents for AGE analysis. FF was a study physician. PG contributed for statistical analysis, PG, NR and ER drafted the manuscript, ER, NR, FF, EW, CGS and PG contributed to acquisition and interpretation of data. All authors read and approved the final version of manuscript.

\section{Acknowledgement}

This work was performed at CIRO +, centre of expertise for Chronic Organ Failure, in Horn, The Netherlands. We thank the COPD patients and the healthy subjects who volunteered to participatein the study. Moreover we are grateful to Trineke Hofstra, BSc; Ans Suntjens, BSc; MarcoAkkermans, BSc; Linda Op 't Veld, MSc; Koen Stakenborg, BSc; Jos Peeters, BSc; MartijnCuijpers, MSc; Annie van de Kruijs, RN; Irma Timmermans, RN; Miriam Groenen, MSc and Riny van Kessel, RN for planning and performing all the tests.

\section{Author details}

'Department of Respiratory Medicine, Maastricht University Medical Center + (MUMC), Maastricht, the Netherlands. ${ }^{2}$ Centre of expertise for chronic organ failure (Ciro+), PO Box 4080, Horn, the Netherlands. ${ }^{3}$ Department of Internal Medicine, Maastricht University Medical Center + (MUMC), Maastricht, the Netherlands.

Received: 18 November 2013 Accepted: 16 February 2014 Published: 25 February 2014

\section{References}

1. Miniati M, Monti S, Basta G, Cocci F, Fornai E, Bottai M: Soluble receptor for advanced glycation end products in COPD: relationship with emphysema and chronic cor pulmonale: a case-control study. Respir Res 2011, 12:37.

2. Coxson HO, Dirksen A, Edwards LD, Yates JC, Agusti A, Bakke P, Calverley PMA, Celli B, Crim C, Duvoix A, et al: The presence and progression of emphysema in COPD as determined by CT scanning and biomarker expression: a prospective analysis from the ECLIPSE study. Lancet Respir Med 2013, 1:129-136.

3. Neeper M, Schmidt AM, Brett J, Yan SD, Wang F, Pan YC, Elliston K, Stern D, Shaw A: Cloning and expression of a cell surface receptor for advanced glycosylation end products of proteins. J Biol Chem 1992, 267:14998-15004.

4. Kumano-Kuramochi M, Ohnishi-Kameyama M, Xie Q, Niimi S, Kubota F, Komba S, Machida S: Minimum stable structure of the receptor for advanced glycation end product possesses multi ligand binding ability. Biochem Biophys Res Commun 2009, 386:130-134. 
5. Hudson BI, Carter AM, Harja E, Kalea AZ, Arriero M, Yang H, Grant PJ, Schmidt AM: Identification, classification, and expression of RAGE gene splice variants. FASEB J 2008, 22:1572-1580.

6. Raucci A, Cugusi S, Antonelli A, Barabino SM, Monti L, Bierhaus A, Reiss K, Saftig P, Bianchi ME: A soluble form of the receptor for advanced glycation endproducts (RAGE) is produced by proteolytic cleavage of the membrane-bound form by the sheddase a disintegrin and metalloprotease 10 (ADAM10). FASEB J 2008, 22:3716-3727.

7. Yamakawa N, Uchida T, Matthay MA, Makita K: Proteolytic release of the receptor for advanced glycation end products from in vitro and in situ alveolar epithelial cells. Am J Physiol Lung Cell Mol Physiol 2011, 300:L516-L525.

8. Tanaka N, Yonekura H, Yamagishi S, Fujimori H, Yamamoto $Y$, Yamamoto $H$ : The receptor for advanced glycation end products is induced by the glycation products themselves and tumor necrosis factor-alpha through nuclear factor-kappa B, and by 17 beta-estradiol through Sp-1 in human vascular endothelial cells. J Biol Chem 2000, 275:25781-25790.

9. Gopal P, Reynaert NL, Scheijen JL, Engelen L, Schalkwijk CG, Franssen FM, Wouters EF, Rutten EP: Plasma advanced glycation end-products and skin autofluorescence are increased in COPD. Euro Resp J 2014, 43(2):430-438.

10. Smith DJ, Yerkovich ST, Towers MA, Carroll ML, Thomas R, Upham JW: Reduced soluble receptor for advanced glycation end-products in COPD. Eur Respir J 2011, 37:516-522.

11. Cockayne DA, Cheng DT, Waschki B, Sridhar S, Ravindran P, Hilton H, Kourteva G, Bitter H, Pillai SG, Visvanathan S, et al: Systemic biomarkers of neutrophilic inflammation, tissue injury and repair in COPD patients with differing levels of disease severity. PLoS One 2012, 7:e38629.

12. Wu L, Ma L, Nicholson LF, Black PN: Advanced glycation end products and its receptor (RAGE) are increased in patients with COPD. Respir Med 2011, 105:329-336.

13. Sukkar MB, Wood LG, Tooze M, Simpson JL, McDonald VM, Gibson PG, Wark PA: Soluble RAGE is deficient in neutrophilic asthma and COPD. Eur Respir J 2012, 39:721-729.

14. Gelb AF, Gold WM, Wright RR, Bruch HR, Nadel JA: Physiologic diagnosis of subclinical emphysema. Am Rev Respir Dis 1973, 107:50-63.

15. Rabe KF, Hurd S, Anzueto A, Barnes PJ, Buist SA, Calverley P, Fukuchi Y, Jenkins C, Rodriguez-Roisin R, Van Weel C, et al: Global strategy for the diagnosis, management, and prevention of chronic obstructive pulmonary disease: GOLD executive summary. Am J Respir Crit Care Med 2007, 176:532-555.

16. Thurlbeck WM: A pathologist looks at respiratory failure due to obstructive lung disease. Chest 1970, 58(2):408+.

17. Clausen JL, Coates AL, Quanjer PH: Measurement of lung volumes in humans: review and recommendations from an ATS/ERS workshop. Eur Respir J 1997, 10:1205-1206.

18. Hanssen NM, Engelen L, Ferreira I, Scheijen JL, Huijberts MS, Van Greevenbroek MM, van der Kallen CJ, Dekker JM, Nijpels G, Stehouwer CD, Schalkwijk CG: Plasma levels of advanced glycation endproducts $\mathrm{N}$ \{epsilon\}-(carboxymethyl)lysine, N\{epsilon\}-(carboxyethyl)lysine, and pentosidine are not independently associated with cardiovascular disease in individuals with or without type 2 diabetes: the HOORN and CODAM studies. J Clin Endocrinol Metab 2013, 98:E1369-E1373.

19. Scheijen $\mathrm{L}$, van de Waarenburg MP, Stehouwer CD, Schalkwijk CG: Measurement of pentosidine in human plasma protein by a single-column high-performance liquid chromatography method with fluorescence detection. J Chromatogr B Analyt Technol Biomed Life Sci 2009, 877:610-614.

20. Cockcroft DW, Gault MH: Prediction of creatinine clearance from serum creatinine. Nephron 1976, 16:31-41.

21. Zhang L, Bukulin M, Kojro E, Roth A, Metz W, Fahrenholz F, Nawroth PP, Bierhaus A, Postina R: Receptor for advanced glycation end products is subjected to protein ectodomain shedding by metalloproteinases. J Biol Chem 2008, 283:35507-35516.

22. Betsuyaku T, Nishimura M, Takeyabu K, Tanino M, Venge P, Xu S, Kawakami $Y$ : Neutrophil granule proteins in bronchoalveolar lavage fluid from subjects with subclinical emphysema. Am J Respir Crit Care Med 1999, 159:1985-1991.

23. Finlay GA, Russell KJ, McMahon KJ, D'Arcy EM, Masterson JB, FitzGerald MX O'Connor CM: Elevated levels of matrix metalloproteinases in bronchoalveolar lavage fluid of emphysematous patients. Thorax 1997, 52:502-506.
24. Higashimoto $Y$, Yamagata $Y$, Iwata T, Okada M, Ishiguchi T, Sato H, Masuda $\mathrm{M}$, Itoh $\mathrm{H}$ : Increased serum concentrations of tissue inhibitor of metalloproteinase-1 in COPD patients. Eur Respir J 2005, 25:885-890.

25. Gaens KH, Ferreira I, van der Kallen CJ, Van Greevenbroek MM, Blaak EE, Feskens EJ, Dekker JM, Nijpels G, Heine RJ, Hart LM T, et al: Association of polymorphism in the receptor for advanced glycation end products (RAGE) gene with circulating RAGE levels. J Clin Endocrinol Metab 2009, 94:5174-5180.

26. Cheng DT, Kim DK, Cockayne DA, Belousov A, Bitter H, Cho MH, Duvoix A, Edwards LD, Lomas DA, Miller BE, et al: Systemic soluble receptor for advanced glycation endproducts is a biomarker of emphysema and associated with AGER genetic variants in patients with chronic obstructive pulmonary disease. Am J Resp Crit Care Med 2013, 188(8):948-957.

27. Peng WH, Lu L, Wang LJ, Yan XX, Chen QJ, Zhang Q, Zhang RY, Shen WF: RAGE gene polymorphisms are associated with circulating levels of endogenous secretory RAGE but not with coronary artery disease in Chinese patients with type 2 diabetes mellitus. Arch Med Res 2009, 40:393-398.

28. Ferhani N, Letuve S, Kozhich A, Thibaudeau O, Grandsaigne M, Maret M, Dombret MC, Sims GP, Kolbeck R, Coyle AJ, et al: Expression of highmobility group box 1 and of receptor for advanced glycation end products in chronic obstructive pulmonary disease. Am J Respir Crit Care Med 2010, 181:917-927.

29. Boschetto P, Campo I, Stendardo M: Plasma sRAGE and N-(carboxymethyl) lysine in patients with CHF and/or COPD. Eur J Clin Invest 2013, 43:562-569.

30. Gopal P, Rutten EP, Dentener MA, Wouters EF, Reynaert NL: Decreased plasma sRAGE levels in COPD: influence of oxygen therapy. Eur J Clin Invest 2012, 42:807-814.

31. Cheng DT, Kim DK, Cockayne DA, Belousov A, Bitter H, Cho MH, Duvoix A, Edwards LD, Lomas DA, Miller BE, et al: Systemic soluble receptor for advanced glycation endproducts is a biomarker of emphysema and associated with ager genetic variants in patients with chronic obstructive pulmonary disease. Am J Respir Crit Care Med 2013, 188:948-957.

32. Hou C, Zhao H, Liu L, Li W, Zhou X, Lv Y, Shen X, Liang Z, Cai S, Zou F: High mobility group protein $B 1$ (HMGB1) in Asthma: comparison of patients with chronic obstructive pulmonary disease and healthy controls. Mol Med 2011, 17:807-815.

33. Schleicher E, Friess U: Oxidative stress, AGE, and atherosclerosis. Kidney Int Supp/ 2007, S17:26.

34. Cheng C, Tsuneyama K, Kominami R, Shinohara H, Sakurai S, Yonekura H, Watanabe T, Takano Y, Yamamoto H, Yamamoto Y: Expression profiling of endogenous secretory receptor for advanced glycation end products in human organs. Mod Pathol 2005, 18:1385-1396.

35. Koyama H, Shoji T, Fukumoto S, Shinohara K, Emoto M, Mori K, Tahara H, Ishimura E, Kakiya R, Tabata T, et al: Low circulating endogenous secretory receptor for AGEs predicts cardiovascular mortality in patients with end-stage renal disease. Arterioscler Thromb Vasc Biol 2007, 27:147-153.

doi:10.1186/1465-9921-15-24

Cite this article as: Gopal et al:: Association of plasma sRAGE, but not esRAGE with lung function impairment in COPD. Respiratory Research 2014 15:24.

\section{Submit your next manuscript to BioMed Central and take full advantage of:}

- Convenient online submission

- Thorough peer review

- No space constraints or color figure charges

- Immediate publication on acceptance

- Inclusion in PubMed, CAS, Scopus and Google Scholar

- Research which is freely available for redistribution 